\title{
Lingvo-Methodical Technology of Applying Elements of Artificial bilingualism in the Process of Teaching English Preschool Children Using the Project Method
}

\author{
Saldaeva Ksenia Vitalievna ${ }^{1}$ \\ ${ }^{1}$ student of Novosibirsk State Pedagogical University, \\ Russia
}

\begin{abstract}
:
This article is devoted to the study of the phenomenon of bilingualism and the use of artificial bilingualism in working with children of preschool age. The article describes the relevance of this technology and features of the educational process for teaching preschool children English in a preschool educational organization. The article substantiates the feasibility of using the project method in working with preschoolers in a specially organized system of artificial bilingualism.
\end{abstract}

Keywords: artificial bilingualism, bilingualism, English, preschoolers, project method.

\section{Introduction}

The main text of the article is devoted to the study of artificial bilingualism and the system of teaching English to preschool children in this system. Modern society is organized in such a way that it requires a person to know several languages. English is one of the languages of international communication, as well as more and more common in our country, so today every person is faced with it in one way or another. Language is an intermediary in communication between people of different countries, provides favorable relations and therefore connects many States and nationalities more and more firmly.

English is one of the most widely spoken languages in the world, so it is taught in most schools. Preschool educational organizations are also interested in teaching preschoolers English, so they create all the opportunities for this.

\section{Body of paper}

Bilingualism is an actively introduced phenomenon in the modern world - the ability of a person to speak several languages at the same time. Its study is devoted to the works of many domestic and foreign researchers (V. Bloomfield [1], E. M. Vereshchagin [2], U. Weinreich [3], G. M. Vishnevskaya [4], V. A. Avrorin [5] and others). 
According to the classical interpretation of bilingualism by U. Weinreich, bilingualism is the simultaneous possession of two languages. Based on the classification, natural and artificial bilingualism are traditionally distinguished. Natural bilingualism means learning two languages from birth, living in a bilingual environment.

Today, the phenomenon of artificial bilingualism, when learning a second language in artificially created conditions, is of the greatest importance and relevance. This is due to the fact that not all parents are able to provide the child with natural conditions for mastering foreign language culture and language.

Artificial bilingualism is a combination of specially selected teaching methods and techniques that are interrelated with the unique personal traits of the teacher. The task of English language teachers is to create the necessary conditions for a favorable and productive teaching of English to children using elements of artificial bilingualism.

The system of teaching preschool children English is different from the system of working with schoolchildren and adults. The main difference is the lack of motivation and the ability to concentrate and memorize purposefully, as well as the need for frequent changes in activities. That is why teachers of English have a problem-to make learning productive by using all the ways to attract children's attention and activate them. For this purpose, teachers develop educational programs for teaching foreign language to children, based on their age characteristics, as well as the goals pursued by parents, etc.

Artificial bilingualism or educational bilingualism, as some researchers call it, is formed outside the language environment, with limited interaction time-usually on the basis of specially created educational situations, lessons. On the one hand, speech practice is limited, and, as a rule, it is not carried out with a native speaker; also, language training does not occur spontaneously, but on the basis of program topics. On the other hand, language phenomena are assimilated systematically, with a professional teacher next to the child who purposefully organizes the learning environment. Also, the teacher is working on errors, which contributes to the most solid consolidation of new information [6].

Preschool children have their own specific age and psychological characteristics, so they need a special approach to organizing English classes. Next, we should consider the features that are typical for preschoolers and, as a result, some of the features that are inherent in the educational process in a preschool educational organization:

1. Lack of motivation to learn English. Students and adults are more aware of this process, as they have a need for it for some reason. Children do not realize this because of their age, and do not perceive language classes as classes - for them it is nothing more than an interesting pastime due to the variety of teaching methods. In this case, relevant training techniques such as a surprise moment, the introduction of a character, playing actions, etc.

2. The leading role of game methods in learning. This provision is related to the leading type of activity of children-play. Thanks to the game, you can attract the attention of children and interest them. The process of language acquisition is perceived by preschoolers as a game, so they learn English with ease and interest, i.e. they learn by playing. Playing as a learning method makes the process of learning English effective.

3. Different types of activities. It is important to note that children of preschool age are not capable of long-term concentration on one activity due to their age. They know the world, they are active, so monotonous activity quickly tires them. In order to keep the interest and children learn the language productively, it is necessary to build a class with a set of different 


\section{SOCIAL SCIENCE, HUMANITIES \& EDUCATION}

types of activity. Here we should talk about teaching English through didactic games, music, outdoor games, theater, etc.

4. Short attention span. One of the features of preschoolers is that they are not able to focus. They are distracted by any slightest external factor (noise, an interesting subject), so the task of the teacher is to skillfully attract and concentrate the child's attention on the lesson in various ways.

5. Short duration of the session. Based on the above, we can note the following situation - the duration of classes with children is limited by the rules. Children get tired quickly, so, for example, for older preschoolers, the duration of the class, which includes a set of different activities for learning English, with physical minutes, is 25-30 minutes.

6. Repeatability of the material. For children, as for adults, it is important to train, repeat the material. Based on this, the work should be organized by the teacher so that the topics are closely related to each other; during the study of new material, elements of the studied material are found; each lesson includes elements of repetition of the passed material.

7. Visualization. The preschooler explores the world, so the main way of knowing the world for him is vision. Children learn to associate with heard clearly, therefore, important cards, pictures, etc.

The relevance of starting learning a foreign language at preschool age has been proved by many researchers, so, based on this, it should be concluded that it is advisable to develop a program of teaching English with the inclusion of elements of artificial bilingualism.

In order to build a favorable interaction between the teacher and children in the process of learning English, as well as the organization of productive work, the teacher builds the work based on the age characteristics of children. Older preschoolers are interested in everything new and interesting, so they learn a foreign language easily and naturally. Preschool children are taught on the basis of communicative, personal and activity approaches. The basis of productive work with children is the interaction of various types of children's activities, various methods and methods of training, as well as contact with the child's family.

A teacher who works with children creates a program that reflects the thematic sections, such as" Family"," Animals"," Fruits"," Hobbies", etc., the words and phrases that children should learn in the learning process, as well as the time that is necessary for this.

Special attention in the training program should be paid to «Festival units» in which it is advisable to organize project activities with children. For example, the holidays "Happy Christmas", "Mother's day", "Easter" can be implemented using a creative approach. During the course of training with children during the year, familiarity with foreign culture is carried out. Together with children, various activities are organized that motivate preschoolers to learn the language and stimulate interest. In particular, the teacher tells children about holidays, creates joint crafts, and studies traditions.

It is possible to implement the project method using non-traditional drawing techniques poking with a cotton swab, brushing with a toothbrush, monotyping, drawing with a palm, drawing with a cereal, drawing with a fork, and blotting. These techniques activate children, increase their motivation, develop memory, attention, thinking and imagination. In addition, during the introduction to new drawing techniques, children learn new words related to simple actions - "cut", "glue", "push, etc. 


\title{
SOCIAL SCIENCE, HUMANITIES \& EDUCATION
}

\section{6 - 8 MARCH 2020}

\author{
BUDAPEST, HUNGARY
}

\section{Conclusion}

Thus, we can conclude that the system of teaching preschool children using elements of artificial bilingualism is relevant today and will be relevant in the coming years, which is due to the need for people who speak several languages. It is most appropriate to start implementing a learning system with elements of artificial bilingualism in pre-school institutions, development centers, and language schools, and to work with children of preschool age in them.

\section{References}

[1] Bloomfield, L. (1968) Language. Moscow: Progress, 608 p.

[2] Vereshchagin, E. M. (2014) Psychological and methodological characteristics of bilingualism (bilingualism). Moscow: Direct-Media, $162 \mathrm{p}$.

[3] Weinreich, U. (1979) Language contact: the state and problems of research. Kiev: Higher school, $246 \mathrm{p}$.

[4] Vishnevskaya, G. M. (1997) Bilingualism and its aspects: textbook. Ivanovo, 98 p.

[5] Avrorin, V. A. (2002) Problems of bilingualism and multilingualism / / Bilingualism and school. Moscow: Science, №6. pp. 49-62.

[6] Denisova, E. A. (2016) Theoretical background to the study of the term "bilingualism" / / international research journal. №11-2 (53), pp. 22-24. 